\title{
Eksistensi taman telajakan pekarangan depan rumah di Banjar Beng Kaja, Desa Tunjuk, Kecamatan Tabanan, Kabupaten Tabanan
}

\author{
I Made Pebri Andi Setiawan ${ }^{1}$, Cokorda Gede Alit Semarajaya ${ }^{2 *}$, \\ Anak Agung Gede Sugianthara²
}

1. Prodi Agroekoteknologi, Fakultas Pertanian, Universitas Udayana, Indonesia

2. Prodi Arsitektur Pertamanan, Fakultas Pertanian, Universitas Udayana, Indonesia

*E-mail: coksemarajaya@unud.ac.id

\begin{abstract}
Existence of Telajakan yard in Beng Kaja, Tunjuk Village, Tabanan District. Telajakan frontyard is a located of the entrance of the house (angkul-angkul) on the left side or right side of house. Telajakan is one of local wisdom of the Balinese people who are now under-scrutiny. In the context of space, telajakan serves to widen the distance of sight, as security of the building, creating familiarity, as well as a place of greening and the identity of an environment, while in the spiritual or religious context, telajakan as part of the ceremonial ritual implementation that sticks penjor at the time of religious ceremony as well as profane in the context of Balinese architecture. The purpose of this research is to the function and development of telajakan in Beng Kaja in its management and preservation. The method used in this research was survey method with observation technique, literature study, interview and questionnaire. The results showed that 32 samples $25 \%$ of the know the concept of the park and $75 \%$ of the residents did not know the concept of telajakan. There were $21.88 \%$ of who know the function of the park and $78.12 \%$ of did not know the function of telajakan. In terms of development of the area, $28.12 \%$ of stated that there was a change in the park and $71.88 \%$ of stated that there was no change. Telajakan in Beng Kaja is not much changed, physically (hardscape) only changes the shape and area of the building while the non-physical (softscape) changes the type of plant.
\end{abstract}

Keywords: Balinese traditional park, Beng Kaja telajakan park, Balinese heritage

\section{Pendahuluan}

Telajakan adalah ruang antara angkul-angkul dengan jalan atau marga dalam Bahasa Bali (Dwijendra, 2010). Taman telajakan adalah taman yang terdapat pada sisi kiri kanan pintu masuk rumah (angkul-angku), karena mengingat dari beberapa jenis telajakan yaitu telajakan pura, telajakan merajan, telajakan kantor, telajakan sekolah, telajakan jalan (media jalan), telajakan telabah (saluran air), telajakan desa, telajakan subak, telajakan puri, dan sebagainya.

Taman telajakan pada umumnya termasuk taman yang mempunyai konsep budaya Bali tidak terlepas dari elemen tanaman sebagai penyusun utama pada taman. Tanaman merupakan elemen untuk mendukung keindahan suatu taman dan pengisi area kosong pekarangan. Estetika dan keindahan suatu taman dipengaruhi oleh factor fisik tanaman yang sesuai dengan fungsi penanaman seperti untuk pagar, naungan, proteksi, pengarah jalan dan sebagainya (Sardiana dkk., 2012)

Dalam pelestarian taman di Bali fungsi telajakan merupakan salah satu ciri kearifan lokal masyarakat dan estetika yang sekarang hampir kurang diperhatikan. Supaya tidak menjadi tempat pembuangan sampah maka telajakan ini dimanfaatkan untuk menanam berbagai macam tanaman hias dan bunga, karena bunga merupakan salah satu sarana sembahyang (Supardiyadnya, 2011). Lansekap yang didominasi oleh elemen vegetasi cenderung lebih disukai masyarakat dan dianggap indah, sedangkan lansekap yang didominasi oleh elemen bangunan cenderung kurang disukai dan dianggap kurang indah atau estetik (Meliawati, 2003 dalam Pasek Harimbawa, 2015). 
Banjar Beng Kaja terletak di Desa Tunjuk Kecamatan Tabanan berbatasan langsung dengan beberapa desa yang terkenal dengan pariwisata alam dan budayanya, seperti Penebel, Jatiluwih dan Marga. Desa-desa yang menjadi daerah tujuan wisata tersebut mulai kehilangan komponen penyusun rumah tradisional, seperti taman telajakan. Hilangnya komponen tersebut dikarenakan alih fungsi lahan taman telajakan yang digunakan sebagai prasarana pendukung kegiatan ekonomi masyarakat. Banjar Beng Kaja juga mengalami alih fungsi lahan taman telajakan namun sangat sedikit. Pentingnya pelestarian taman telajakan merupakan suatu daya tarik tersendiri bagi pariwisata. Identifikasi taman telajakan di banjar Beng Kaja perlu untuk diteliti dalam penelitian ini, sehingga dapat menambah pengetahuan tentang fungsi dan perkembangan taman telajakan yang merupakan salah satu warisan leluhur yang harus tetap dilestarikan.

Berdasarkan latar belakang di atas, maka rumusan masalah yang diangkat adalah sebagai berikut: 1) Bagaimana keberadaan taman telajakan di Banjar Beng Kaja, Desa Tunjuk, Tabanan; 2) Bagaimana fungsi taman telajakan di Banjar Beng Kaja, Desa Tunjuk, Tabanan; 3) Bagaimana perubahan taman telajakan di Banjar Beng Kaja, Desa Tunjuk, Tabanan. Adapun tujuan dari penelitian ini adalah 1) Mengidentifikasi taman telajakan di Banjar Beng Kaja, Desa Tunjuk, Tabanan; 2) Mengidentifikasi fungsi taman telajakan di Banjar Beng Kaja, Desa Tunjuk, Tabanan; 3) Mengetahui perubahan taman telajakan di Banjar Beng Kaja, Desa Tunjuk, Tabanan.

\section{Metodelogi Penelitian}

\subsection{Waktu dan Tempat Penelitian}

Penelitian ini berlokasi di Banjar Beng Kaja, Desa Tunjuk, Kabupaten Tabanan. Pengumpulan data di lapangan pada bulan April sampai dengan Juni 2016.

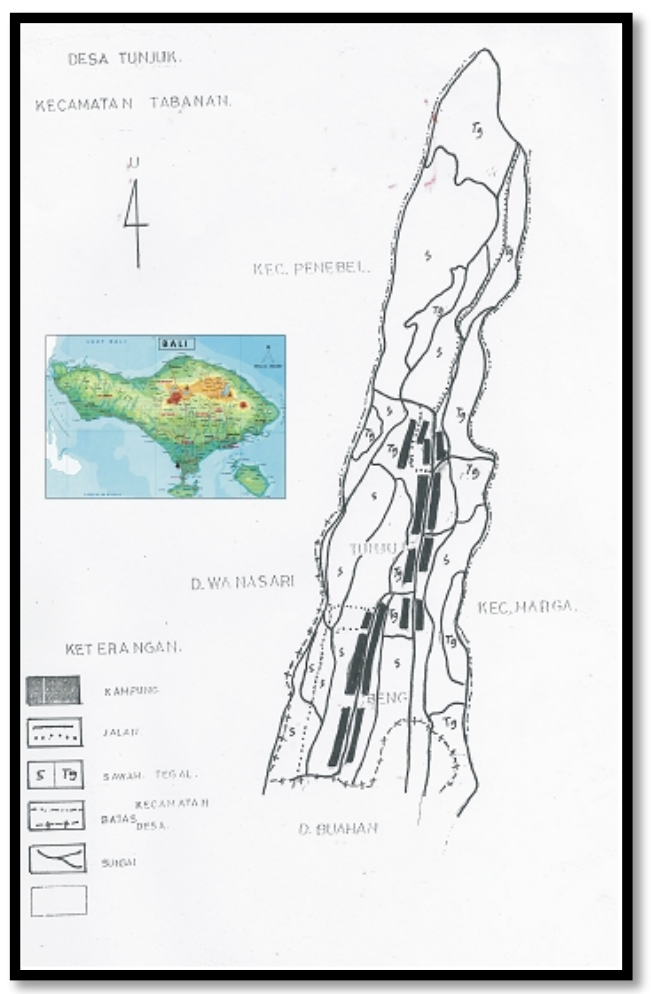

Gambar 1. Peta Lokasi Penelitian

\section{2. $\quad$ Alat Penelitian}

Alat yang digunakan untuk melakukan penelitian antara lain adalah meteran, kamera digital, kuisioner dan perangkat computer (Microsoft Office Word, Microsoft Office Excel Dan Photoshop). 


\subsection{Metode Penelitian}

Metode penelitian yang digunakan adalah metode survey. Jenis data yang digunakan dalam penelitian adalah data primer dan data sekunder. Data primer berupa hasil observasi, penyebaran kuesioner dan wawancara di lapangan, sedangkan data sekunder diperoleh berdasarkan studi kepustakaan.

Cara pengambilan sampel dalam penelitian ini menggunakan teknik purposive sampling, ditetapkan sebanyak 32 rumah (50\% dari jumlah rumah yang memiliki taman telajakan) yang dianggap dapat mewakili seluruh pemilik taman telajakan. Penelitian ini dilakukan di banjar Beng Kaja Tabanan.

\subsection{Analisis Data}

Data yang telah diperoleh di lapangan selanjutnya dilakukan tabulasi analisis secara deskriptif (Warsito, 1992). Data yang bersifat kuantitatif akan ditampilkan dalam bentuk tabel yang telah diolah dengan rumus:

$$
P=\frac{f}{n} \times 100 \%
$$

Keterangan :

$P=$ Presentase

$f=$ Frekuensi

$n=\sum$ Total Responden

\section{Hasil dan Pembahasan}

\subsection{Identifikasi Taman Telajakan Banjar Beng Kaja}

Pengetahuan warga masih kurang terhadap taman telajakan, dikarenakan kurangnya kesadaran dan kepedulian warga terhadap lingkungan sekitarnya salah satunya adalah taman telajakan. Keberadaan taman telajakan didepan rumah hampir tidak disadari oleh warga Beng Kaja, sehingga yang terjadi adalah kurangnya penataan dan perawatan terhadap taman telajakan baik dari segi bangunannya maupun jenis tanamannya.

\subsection{Filosofi Penempatan Tanaman}

Filosofi penanamannya yang baik ditanam pada area taman telajakan adalah kaktus/belatung gada (Pachycereus Sp.) dan pohon dadap wong (Erythrina variegata) dianggap sebagai tanaman penolak bala dan diyakini dapat menangkal maksud-maksud yang tidak baik. Sehingga biasanya ditanam di sebelah kanan sebelum pintu masuk pekarangan. Ada juga tanaman yang ditanam difungsikan sebagai upakara keagamaan yaitu: dapdap, digunakan dalam upacara pemegat karya, katik sibuh pepek, padanggal, negtegan, ngenteg linggih, pawintenan, alat metatah (potong gigi) dan lis pebuan dan lain-lain. Daun kayu sisih, daunnya digunakan untuk upakara pebyakaonan, prayascita, penglukatan, lis slepanan dan lain-lain.

\subsection{Fungsi Taman Telajakan Banjar Beng Kaja}

Secara fisik ada tiga fungsi utama dari taman telajakan yaitu sebagai penghijauan, menjaga lingkungan dan mempertahankan sempadan bangunan demi keamanan dan kenyamanan bangunan serta lingkungannya (Dwijendra, 2010). Dalam konteks ruang, warga yang mengetahui fungsi dari taman telajakan memanfaatkan taman telajakan sebagai tempat menjemur hasil pertanian, keamanan bangunan, menciptakan keakraban, sebagai tempat menaruh ayam kurungan (aduan), sebagai tempat meletakkan patung diantara angkul-angkul, serta berfungsi memperlebar jarak pandang. Dalam konteks spiritualnya, taman telajakan sebagai tempat menancapkan penjor pada saat hari raya umat Hindu yaitu Galungan dan Kuningan serta sebagai area profan lainnya sedangkan dalam konteks nasionalisme taman telajakan juga digunakan sebagai tempat menamcapkan bendera.

\subsection{Perubahan Taman Telajakan Banjar Beng Kaja}

Perubahan pada taman telajakan akan terjadi dari waktu ke waktu seiring berkembangnya jaman. Perubahan yang dimaksud adalah perubahan fisik maupun non fisik. Perubahan fisik merupakan perubahan kondisi bangunan (hard scape) baik bentuk dan luas bangunan, sedangkan perubahan non fisik (soft scape) adalah perubahan jenis tanaman. 
Berdasarkan penelitian yang telah dilakukan, hasil yang didapatkan menunjukkan bahwa 28,12\% warga menyatakan adanya perubahan ukuran taman telajakan dan $71,88 \%$ menyatakan tidak terjadi perubahan pada taman telajakan.

Secara fisik, taman telajakan banjar Beng Kaja tidak semua mengalami perubahan, hanya ada beberapa taman telajakan yang mengalami perubahan seperti luasan dan bentuk bangunan. Perubahan ini terjadi dikarenakan penambahan luasan bangunan rumah yang mengakibatkan penyempitan luas taman telajakan. Hal lain yang menyebabkan perubahan luasan taman telajakan dipengaruhi oleh pembangunan jalan raya dan saluran pelebaran drainase (got).

Berbeda dengan perubahan secara non fisik, jenis tanaman yang ditanam saat ini sudah mengalami banyak perubahan dan perkembangan jika dibandingkan dengan dua dekade sebelumnya (Tabel 3. dan Tabel 4.).

Tabel 3. Jenis Tanaman yang Ditanam pada Area Taman Telajakan di Banjar Beng Kaja Periode Tahun 1990.

\begin{tabular}{ccccc}
\hline No & Nama Lokal & Nama Latin & Jumlah & Persentase (\%) \\
\hline 1 & Akasia & Acacia denticulosa & 2 & 0,63 \\
2 & Kamboja & Plumeria sp. & 33 & 10,41 \\
3 & Kelapa & Cocos nucifera & 88 & 27,76 \\
\hline 4 & Pisang & Musa sp. & 31 & 9,78 \\
5 & Puring & Codiaeum variegatum & 163 & 51,42 \\
\hline
\end{tabular}

Tabel 3. menunjukkan bahwa pada periode tanaman tahun 1990-an, tanaman puring (Codiaeum variegatum) merupakan tanaman yang paling banyak ditanaman pada area taman telajakan sebanyak 163 pohon $(51,42 \%)$, kelapa sebanyak 88 pohon $(27,76 \%)$, kamboja sebanyak 33 pohon $(10,41 \%)$, pisang sebanyak 31 pohon $(9,78 \%)$ dan akasia sebanyak 2 pohon $(0,63 \%)$. Banjar Beng Kaja saat itu identik dengan tanaman puring, karena pada saat itu puring digunakan juga untuk penyengker (tembok pembatas) oleh masyarakat setempat selain menggunakan bangunan beton.

Tabel 4. Jenis Tanaman yang Ditanam pada Taman Telajakan di Banjar Beng Kaja Periode Tahun 2016.

\begin{tabular}{|c|c|c|c|c|c|}
\hline No & Jenis Tanaman & Nama Lokal & Nama Latin & Jumlah & $\begin{array}{c}\text { Persentase } \\
\%\end{array}$ \\
\hline \multirow[t]{9}{*}{1} & Pohon & Belimbing & Averrhoa carambola & 1 & 3.13 \\
\hline & & Cempaka & Magnolia champaca & 7 & 21.88 \\
\hline & & Jambu Biji & Psidium guajava & 1 & 3.13 \\
\hline & & Kelapa & Cocos nucifera & 8 & 25 \\
\hline & & Mangga & Mangifera indica & 3 & 9.38 \\
\hline & & Mengkudu & Morinda citrifolia & 2 & 6.25 \\
\hline & & Nangka & Artocarpus heterophyllus & 3 & 9.38 \\
\hline & & Sandat & Cananga odorata & 6 & 18.75 \\
\hline & & Sirsak & Annona muricata & 1 & 3.13 \\
\hline \multirow[t]{5}{*}{2} & Perdu & Cemara Norfolk & Araucaria heterophylla & 1 & 0.33 \\
\hline & & Dapdap & Erythrina variegata & 3 & 0.98 \\
\hline & & Kaktus & Cactaceae & 2 & 0.65 \\
\hline & & Kamboja & Plumeria sp. & 76 & 24.76 \\
\hline & & Kembang Kertas & Bougainvillea spectabilis & 36 & 11.73 \\
\hline
\end{tabular}


Lanjutan Tabel 4

\begin{tabular}{|c|c|c|c|c|c|}
\hline No & Jenis Tanaman & Nama Lokal & Nama Latin & Jumlah & $\begin{array}{c}\text { Persentase } \\
\%\end{array}$ \\
\hline & & Mawar & Rosa sp. & 10 & 3.26 \\
\hline & & Melati & Jasminum sp. & 5 & 1.63 \\
\hline & & Pacar Air & Impatiens balsamina & 6 & 1.95 \\
\hline & & Palem Kuning & Chrysalidocarpus lutescens & 14 & 4.56 \\
\hline & & Perasok & Cordyline australis & 10 & 3.26 \\
\hline & & Puring & Codiaeum variegatum & 107 & 34.85 \\
\hline & & Pucuk Merah & Syzygium oleana & 5 & 1.63 \\
\hline & & Tunjang Langit & Schefflera Sp. & 4 & 1.30 \\
\hline & & Aglonema & Aglaonema crispum & 27 & 8.79 \\
\hline & & Daun Kayu Sisih & Phyllanthus buxifolius & 1 & 0.33 \\
\hline \multirow[t]{6}{*}{3} & Semak & Daun Sirih & Piper betle & 2 & 1.48 \\
\hline & & Euphorbia & Euphorbia milii & 25 & 18.52 \\
\hline & & Iris Kuning & Iris pseudacorus & 52 & 38.52 \\
\hline & & Lidah Mertua & Sansevieria & 28 & 20.74 \\
\hline & & Soka & Ixora & 23 & 17.04 \\
\hline & & Talas Hijau & Colocasia esculenta & 5 & 3.70 \\
\hline \multirow[t]{3}{*}{4} & Penutup Tanah & Rumput Gajah Mini & Pennisetum purpureum & 26 & 33.77 \\
\hline & & Rumput Grinting & Cynodon dactylon & 39 & 50.65 \\
\hline & & Rumput Jepang & Zoysia japonica & 12 & 15.58 \\
\hline
\end{tabular}

Berbeda halnya dengan periode tahun 2016 - sampai sekarang, jenis tanaman-tanaman penyusun taman telajakan cukup beragam dengan berbagai macam jenis tanaman yang ditanam. Berdasarkan jenisnya dibagi menjadi 4 jenis tanaman yaitu; pohon, perdu, semak dan penutup tanah.

Jenis tanaman pohon yang ditanam pada taman telajakan Banjar Beng Kaja meliputi; belimbing (Averrhoa carambola), cempaka (Magnolia champaca), jambu biji (Psidium guajava), kelapa (Cocos nucifera), mangga (Mangifera indica), mengkudu (Morinda citrifolia), nangka (Artocarpus heterophyllus), sandat (Cananga odorata) dan sirsak (Annona muricata). Jenis tanaman pohon yang paling banyak ditanaman pada taman telajakan yaitu: kelapa sebanyak 8 pohon (25\%), cempaka sebanyak 7 pohon $(21,88 \%)$, dan sandat sebanyak 6 pohon $(18,75 \%)$. Kemudian jenis tanaman pohon yang paling sedikit ditanam pada taman telajakan yaitu: belimbing, jambu biji, dan sirsak masing-masing sebanyak satu pohon $(3,13 \%)$.

Jenis tanaman perdu yang ditanaman pada taman telajakan Banjar Beng Kaja meliputi: cemara norfolk (Araucaria heterophylla), dapdap (Erythrina variegata), kaktus (Cactaceae), kamboja (Plumeria sp.), kembang kertas (Bougainvillea spectabilis), mawar (Rosa sp.), melati (Jasminum sp.), pacar air (Impatiens balsamina), palem kuning (Chrysalidocarpus lutescens), perasok (Cordyline australis), puring (Codiaeum variegatum), pucuk merah (Syzygium oleana), tujang langit (Schefflera Sp), aglonema (Aglaonema crispum) daun kayu sirih (Phyllanthus buxifolius). Jenis tanaman perdu yang paling banyak ditanam pada taman telajakan yaitu puring sebanyak 107 pohon (34,85\%), kamboja sebanyak 76 pohon (24,76\%), dan kembang kertas sebanyak 36 pohon (11,73\%). Sedangkan yang paling sedikit ditanam yaitu; cemara norfolk dan daun kayu sisih masing-masing satu pohon $(0,33 \%)$.

Jenis tanaman semak yang ditanam pada taman telajakan meliputi: daun sirih (Piper betle), euphorbia (Euphorbia milii), iris kuning (Iris pseudacorus), lidah mertua (Sansevieria), soka (Ixora sp) dan talas hijau (Colocasia esculenta). Jenis tanaman semak yang paling banyak ditanam pada taman telajakan 
yaitu; iris kuning sebanyak 52 pohon (38,52\%), dan lidah mertua sebanyak 28 pohon (20,74\%), sedangkan tanaman yang paling sedikit ditanam pada taman telajakan yaitu daun sirih sebanyak dua pohon $(1,48 \%)$.

Selain itu juga, jenis tanaman penutup tanah yang ditanam pada teman telajakan meliputi: rumput gajah mini (Pennisetum purpureum), rumput grinting (Cynodon dactylon) dan rumput jepang (Zoysia japonica). Jenis tanaman penutup tanah yang paling banyak ditanam yaitu: rumput grinting seluas $39 \mathrm{~m} 2$ $(50,65 \%)$ dan yang paling sedikit ditanam yaitu rumput jepang seluas $12 \mathrm{~m} 2$ (15,58\%). Pemilihan rumput grinting sebagai penutup tanah karena dalam perawatannya sangat mudah

Perubahan dan perkembangan taman telajakan Banjar Beng Kaja di mulai pada tahun 1990 sampai 1998. Pada tahun tersebut taman telajakan mulai difungsikan sesuai dengan kegiatan masyarakat seperti tempat menjemur hasil pertanian, menaruh ayam kurungan (aduan), tempat menanam tanaman, tempat berinteraksi dan tempat bersantai. Taman telajakan masih berbentuk alami sesuai dengan situasi dan keadaan tapaknya. Taman telajakan ditanam berbagai macam jenis tanaman yang di antaranya akasia (Acacia denticulosa), kamboja (Plumeria sp.), kelapa (Cocos nucifera), pisang (Musa sp), puring (Codiaeum variegatum) dan lain-lain (Suamba, wawancara 24 April 2016).

Pada periode tahun 2000 dan 2016 - sampai sekarang, penataan taman telajakan dalam keadaan baik. Saat ini dilakukan pengelolaan dan perawatan untuk tetap menjaga taman telajakan. Kesadaran masyarakat akan pentingnya menjaga taman telajakan mulai dirasakan terlihat dari masyarakat yang antusias mempertahankan serta menjaga keasrian taman telajakan.

Pengelolaan dan perawatan taman telajakan ini penting dilakukan karena taman telajakan juga dapat digunakan sebagai daya tarik wisata. Pertamanan tradisional Bali kental akan filosofi setiap tanaman yang ditanam pada taman telajakan. Banjar Beng Kaja juga terdapat suatu tempat wisata Taman Sari Buwana (traditional farming) yang merupakan suatu daerah tujuan wisata domestik maupun mancanegara. Salah satu kegiatan yang dilakukan adalah dengan mengajak wisatawan berinteraksi dengan alam dan sosial masyarakat setempat. Setiap wisatawan akan diajak berkunjung kerumah-rumah warga, selain ikut terlibat dalam kegiatan keseharian warga, wisatawan juga bisa terlibat dalam acara adat budaya dan keagamaan.

Kurangnya kegiatan penataan dan perawatan taman telajakan baik dalam ruang lingkup keluarga, banjar, maupun desa merupakan salah satu kemunduran pelestarian taman tradisional Bali. Kegiatan yang dilakukan hanya terbatas pada bersih-bersih lingkungan yang dilakukan pada saat menjelang acara tertentu seperti lomba lingkungan hidup setiap tahunnya dan lomba kebersihaan tingkat desa. Kegiatan demikian tentu tidak optimal dalam menjaga dan melesatarikan taman telajakan, sebab kegiatan tidak berkelanjutan sehingga antusias masyarakat hanya terbatas pada kegiatan lomba. Berbeda halnya dengan daerah lain di Bali, kegiatan pelestarian taman telajakan wajib dijaga dan dilestarikan yang sudah termuat dalam hukum adat (awig-awig) contohnya adalah Desa Adat Nyuh Kuning, Ubud, Gianyar (Awig-awig Desa Adat Nyuh Kuning,1994). Adanya hukum adat tertulis secara tidak langsung mewajibkan masyarakat menjaga dan melestarikan taman telajakan.

\subsection{Komponen Penyusun Taman Telajakan}

Taman telajakan tidak terlepas dari komponen penyusun taman, komponen-komponen tersebut terdiri dari patung, termbok pembatas, tempat menancapkan penjor dan bendera, tanaman, lampu taman dan bangunan taman. Dari semua komponen tersebut tidak semua warga menggunakan komponen tersebut. Patung (sculpture) adalah patung yang ditempatkan didepan angkul-angkul berjumlah dua patung (berpasangan) dan dipercaya berfungsi sebagai penjaga pemilik rumah, patung ini biasanya disesuaikan oleh si pemilik rumah. 


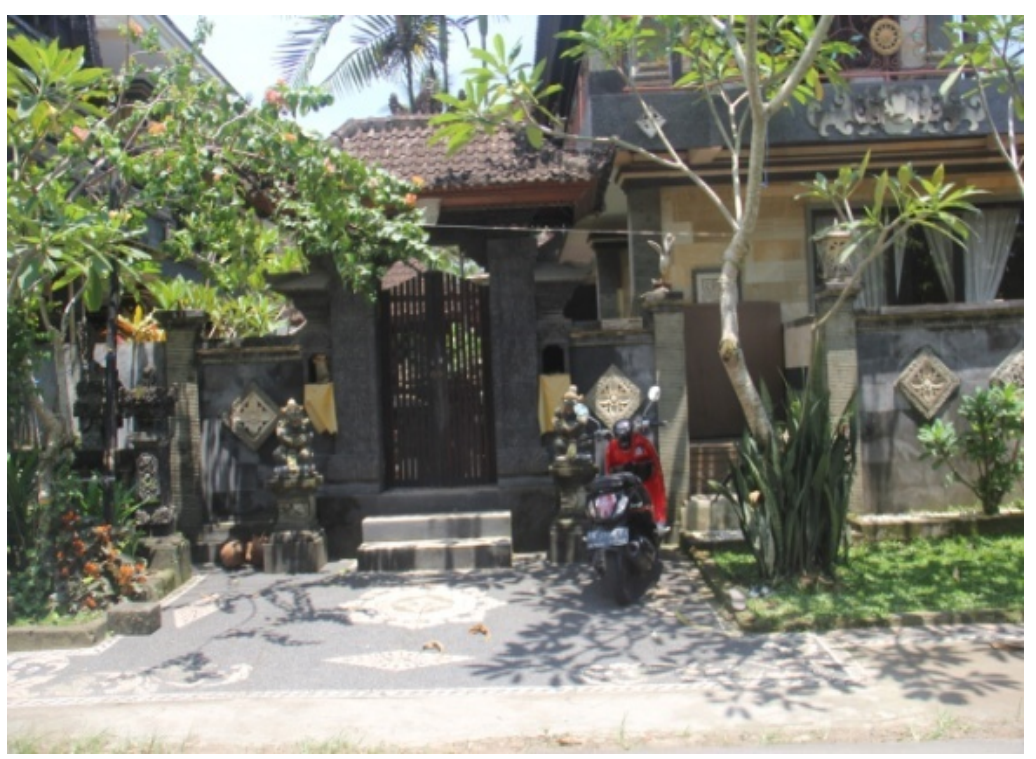

Gambar 1. Patung pada telajakan

Tembok pembatas (penyengker) adalah tembok pembatas antara pekarangan rumah dengan area luar pekarangan, yang biasanya lengkap dengan paduraksa (pertemuan diantara sudut tembok) yang memiliki makna magis sebagai perlindungan.

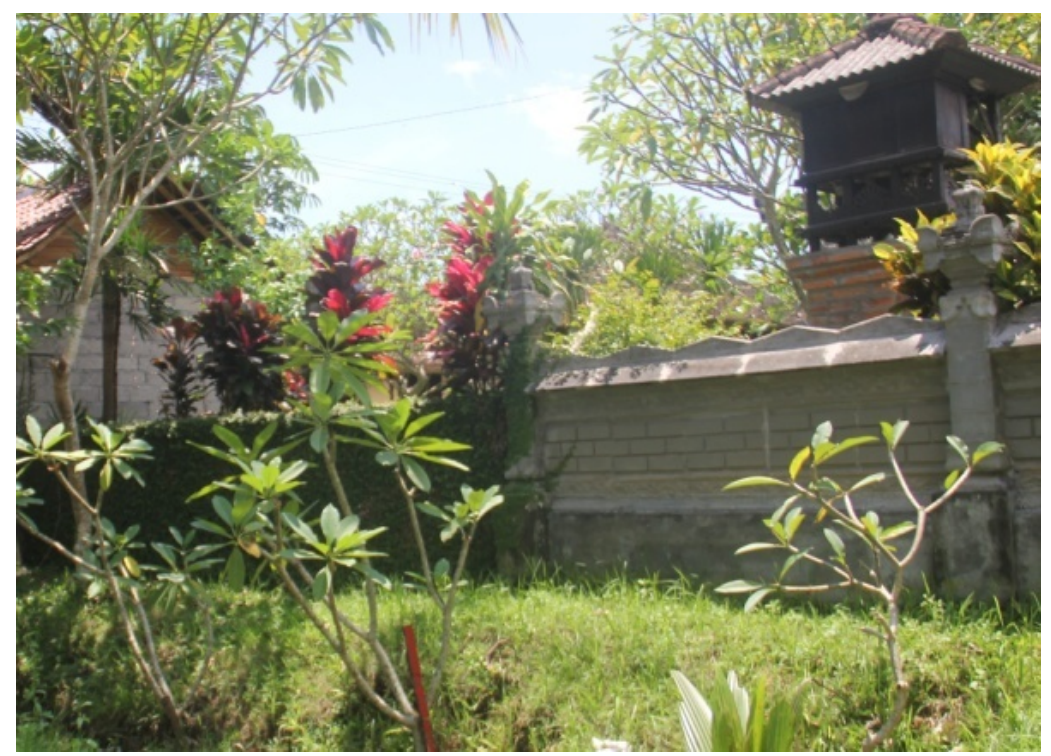

Gambar 2. Tembok pembatas (penyengker) pada telajakan

Tempat menancapkan penjor dan bendera yang bentuknya berupa lubang dengan diameter yang disesuaikan oleh pemilik rumah dengan ukuran bambu (penjor) atau kayu yang digunakan namun biasanya ada juga yang memakai sendi (beton atau marmer) yang ditancapkan kayu dan diletakkan didepan rumah. 


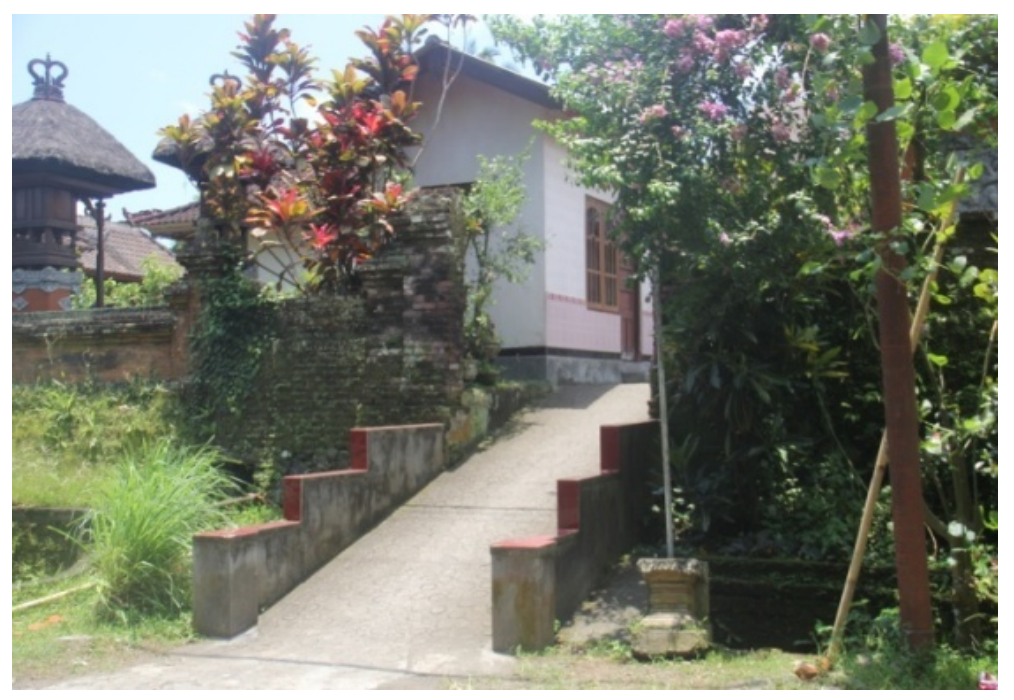

Gambar 3. Tempat penjor dan bendera pada telajakan

Tanaman merupakan komponen yang sangat penting dalam taman telajakan. Berbagai jenis tanaman yang ditanam seperti pohon, perdu, semak dan penutup tanah ditanam pada area taman telajakan dari tanaman lokal sampai tanaman bukan lokal. Pada umumnya tanaman pada area taman telajakan berfungsi sebagai tanaman pelindung maupun tanaman hias namun ada juga tanaman yang memiliki nilai filosofi dan jenis tanaman yang ditanam juga dapat digunakan sebagai tanaman upakara. Jenis tanaman yang digunakan dan penataannya sesuai dengan keinginan si pemilik taman telajakan.
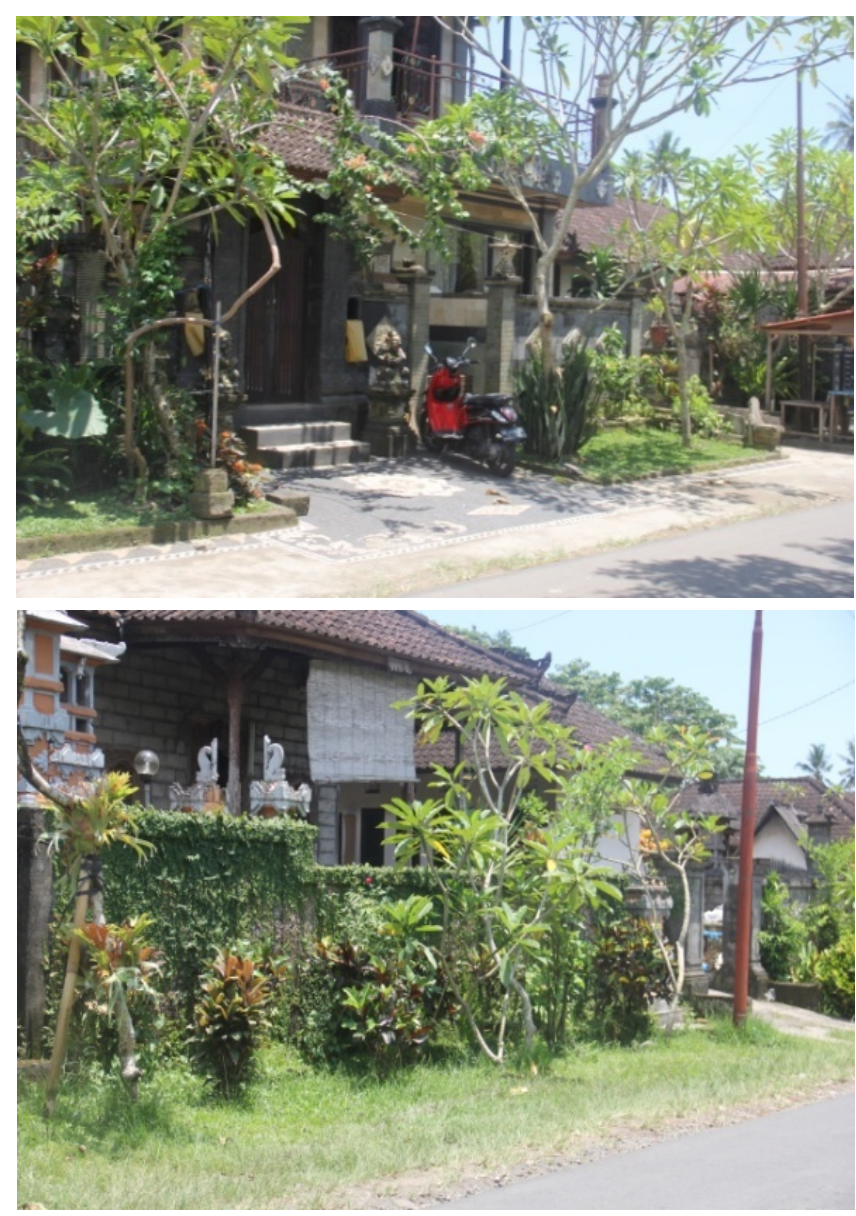

Gambar 4. Keragaman tanaman pada taman telajakan 
Lampu taman difungsikan sebagai penerangan taman telajakan pada malam hari, biasanya model dan bentuknya disesuaikan dengan selera pemilik. Lampu taman diletakkan pada tembok penyengker.

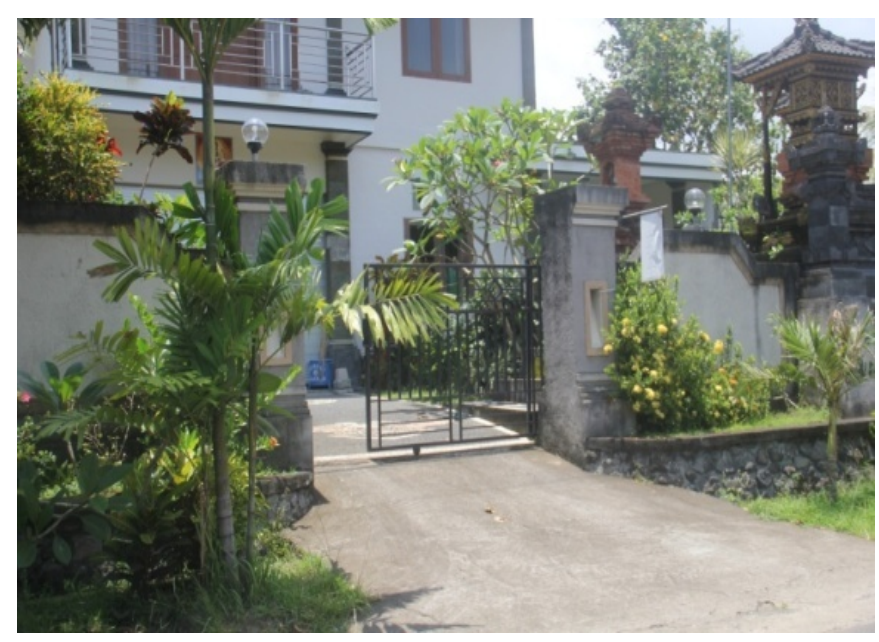

Gambar 5. Lampu taman pada telajakan

Bangunan taman yakni tempat sebagai penyangga tanah dan tanaman agar tidak terjadi erosi saat hujan, yang bentuk dan bahannya terbuat dari batako atau bata.
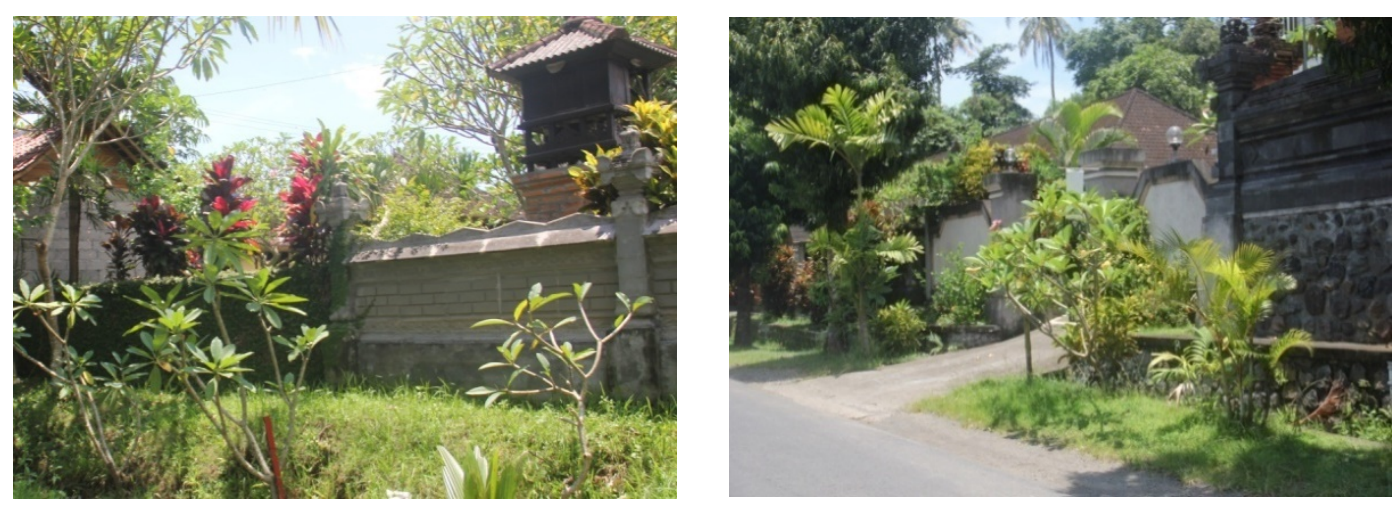

Gambar 6. Bangunan taman

Namun tidak semua taman telajakan di Banjar Beng Kaja membuat bangunan taman, masih ada taman yang alami tanpa adanya bangunan taman.

\section{Simpulan dan Saran \\ 4.1 Simpulan}

Hasil penelitian ini menyimpulkan beberapa hal sebagai berikut:

1. Keberadaan taman telajakan di depan rumah hampir tidak disadari. Kebanyakan warga hanya merawat tanaman yang sudah ada sehingga secara visual terlihat kaku. Keadaan seperti ini akan mengurangi makna keindahan dan filosofi tanaman yang ditanam pada areal taman telajakan, namun ada juga warga yang memperhatikan keberadaan taman telajakan dengan cara menanam dan merawat tanaman yang memiliki nilai keindahan dan sarat akan makna filosofi.

2. Pengetahuan warga terhadap fungsi taman telajakan masih kurang, terdapat $78,12 \%$ responden tidak mengetahui fungsi taman telajakan dan 21,88\% responden yang mengetahui fungsi taman telajakan. 
3. Taman telajakan di banjar Beng Kaja tidak banyak mengalami perubahan, secara fisik (hard scape) hanya terjadi perubahan bentuk dan luas bangunan sedangkan secara non fisik (soft scape) terjadi perubahan jenis tanaman selama dua dekade terakhir.

\subsection{Saran}

Beberapa hal yang disarankan dari penelitian ini antara lain:

1. Perlu dilakukan penelitian lebih lanjut mengenai konsep dan fungsi taman telajakan diberbagai daerah lainnya sebagai sumber acuan referensi dikemudian hari.

2. Pentingnya peran warga, aparat desa, dan pemerintah untuk tetap menjaga eksistensi taman telajakan sebagai salah satu warisan leluhur taman tradisional Bali.

\section{Daftar Pustaka}

Amirin, T.M. 2012. Populasi dan Sampel Penelitian 3: Pengambilan sampel dari populasi Tak-Terhingga dan Tak-Jelas. Wordpress. 30 Juni 2009. Antariksa. Tersedia secara online di: http://tatangmanguny.wordpress.com. (Diakses tanggal 26 Januari 2016).

Dwijendra, N.K.A. 2010. Arsitektur Rumah Tradisional Bali. Udayana University Press. Denpasar

Pasek Harimbawa, I Wayan. 2015. Pengaruh Alih Fungsi Telajakan Depan Rumah Menjadi Artshop terhadap Kenyamanan dan Estetika Lansekap Desa Tegallalang. Skripsi. Fakultas Pertanian, Universitas Udayana. Denpasar.

Sardiana, IK., N.M. Wiasti dan N. Wardi. 2012. Etnobotani Bali. Denpasar: Udayana University Press

Suamba, Wayan. Wawancara Pribadi. 24 April 2016. Banjar Beng Kaja, Desa Tunjuk, Tabanan.

Supardiyadnya. 2011. Kearifan Lokal (Local Genius). Tersedia secara online di: http://meyadnya.blogspot.co.id/2011/09/kearifan-lokal-local-genius_26.html. (Diakses tanggal 21 Januari 2016).

Warsito, Hermawan. 1992. Pengantar Metodologi Penelitian. Gramedia Pustaka Utama. Jakarta 